\title{
Electrochemical sensing platform of natural estrogens based on the poly(L-proline)-ordered mesoporous carbon composite modified glassy carbon electrode
}

\author{
Liqiang Luo, Fang Li, Limei Zhu, Yaping Ding, Dongmei Deng \\ Department of Chemistry, Shanghai University, Shanghai 200444, P R. China \\ Corresponding author's e-mail address: Iuoliqw@yahoo.com.cn
}

\begin{abstract}
:
A novel poly(L-proline)-ordered mesoporous carbon film with controllable thickness on the glassy carbon electrode surface was fabricated by electropolymerization and further used for the construction of electrochemical sensing platform of natural estrogens. Scanning electron microscopy, fourier transform infrared spectroscopy and electrochemical impedance spectroscopy were employed to characterize the surface morphology, structure and interface property of the polymer. The voltammetric behaviors of estrogens involving estradiol, estrone and estriol were investigated on the modified electrode, and the proposed electrode exhibits strong electrocatalytic activity toward the oxidation of three estrogens, especially for estradiol oxidation. Under the optimum conditions, the linear range of estradiol obtained by square-wave voltammetric determination was $1.0 \times 10^{-8}-2.0 \times 10^{-6}$ $\mathrm{mol} / \mathrm{L}$ with a low detection limit of $5.0 \times 10^{-9} \mathrm{~mol} / \mathrm{L}$. The developed modified electrode was applied for the determination of estradiol in female blood serums with satisfactory results.
\end{abstract}

Key words: Ordered mesoporous carbon, L-proline, Electropolymerization, Natural estrogens, Estradiol

\section{Introduction}

Natural estrogens, also called endogenous estrogens, mainly involving estradiol, estrone and estriol, are essential bioactive substance of 18 carbon steroid. Among them, estradiol is the most potent and active estrogen primarily generated by the ovary, and estrone and estriol are the metabolites of estradiol with limited estrogenic activity. Three estrogens take part in intracellular communication, affecting the development and maintenance of sex characteristics, and their concentrations and changes are closely related to human's health status [1-3]. Thus, the determination of natural estrogens is of great importance. Owning to the operational simplicity, low expense, fast response and high sensitivity, electroanalytical method attracts great concern and a variety of modified electrodes have been reported for estrogens determination. For example, a nano$\mathrm{Al}_{2} \mathrm{O}_{3}$ film modified glassy carbon electrode (GCE) [4], a Congo red-functionalized multiwalled carbon nanotubes (MWNTs) modified GCE [5], a MWNTs-Nafion modified GCE [6], a poly(L-serine) film-modified GCE [7], a DNA aptamer immobilized gold electrode chip [8] and a boron doped diamond thin film electrode [9] have been put forward to detect estradiol.
Ordered mesoporous carbon (OMC), with wellordered structures and unique properties, is an excellent electrode modified material, and has been widely used in electroanalysis [10-12]. To achieve OMC modified electrode, several methods have been developed [12-14], mainly by directly casting OMC dispersion onto the electrode surface $[11,12]$. However, in this way, the thickness of the resulting film was not easy to be controlled, and the poor surface coverage of OMC on the substrate electrode often leads to large interfacial capacitance [14, 15].

To the best of our knowledge, the fabrication of $\mathrm{OMC}$ film on the surface of electrode by direct electrodeposition technique has not been reported. In this work, OMC film was deposited on GCE surface, and a novel polymer of poly(Lproline)-OMC film (PPOMC) was prepared by multicyclic voltammetry scanning in the mixed solution of L-proline and OMC. The obtained PPOMC modified GCE exhibits strong electrocatalytic activity toward the oxidation of three natural estrogens. This makes PPOMC/GCE a promising electrochemical sensing platform for sensitive detection of estrogens. 


\section{Experimental \\ Synthesis of OMC}

OMC was synthesized using template method in which SBA-15 acted as the template and sucrose acted as the carbon source, and the detailed preparation of OMC has been published in other reports $[16,17]$.

\section{Electrode modification}

The PPOMC/GCE was prepared by electropolymerization of GCE in the black suspension of $1 \mathrm{mg} \mathrm{OMC}$ and $10 \mathrm{mmol}$ L-proline

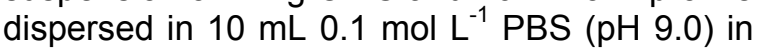
the potential range of $-0.8 \mathrm{~V}$ to $2.4 \mathrm{~V}$ for 10 cycles (Fig. 1).

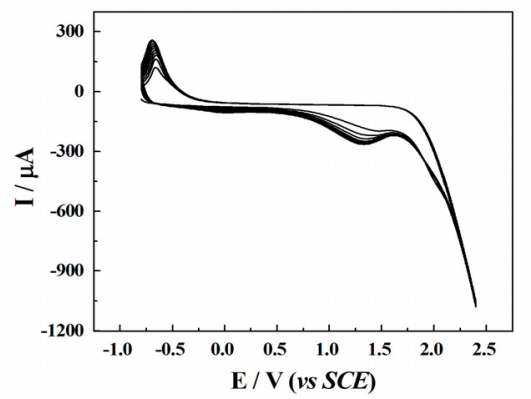

Fig. 1. The electropolymerization of PPOMC on GCE surface was carried out using cyclic sweeps between $-0.8 \mathrm{~V}$ and $2.4 \mathrm{~V}$ for 10 cycles in $0.1 \mathrm{~mol} \mathrm{~L}^{-1}$ PBS (pH 9.0) containing $1 \mathrm{mmol}^{-1}$ L-proline and 0.1 $m g m L^{-1}$ OMC.

\section{Results and discussion \\ Characterization by SEM and FTIR spectra}

The typical morphologies of PPOMC film (Fig. 2) and OMC film obtained by deposition (the inset) were observed by SEM. The inset of Fig. 2 shows that OMC film is made up of linked ordered fingerlike carbon flakes, which indicates that the structure of OMC film could significantly increase the effective electrode surface. Compared with OMC film, the PPOMC film is characterized by light dots which suggests that L-proline has been incorporated into or modified on the OMC film.

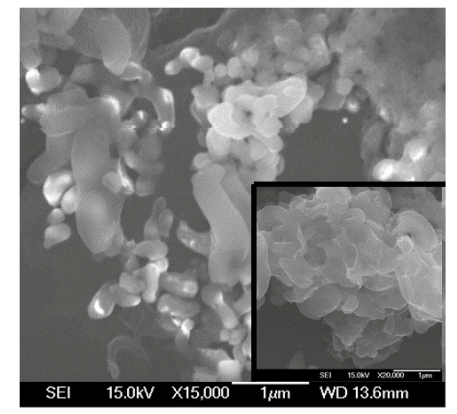

Fig. 2. SEM of PPOMC and the inset shows the SEM image of OMC film.
Further more, in order to demonstrate OMC and L-proline have been electropolymerized on the surface of GCE, FTIR spectra of OMC (a), Lproline (b) and PPOMC film (c) were analyzed in the range of $400-4000 \mathrm{~cm}^{-1}$, as can be seen in Fig. 3. In curve (a), the band around $1650 \mathrm{~cm}^{-1}$ is attributed to $\mathrm{C}=\mathrm{O}$ stretch vibration, and the band around $1150 \mathrm{~cm}^{-1}$ is assignable to $\mathrm{C}-\mathrm{O}$ stretch vibration, while the band around 3450 $\mathrm{cm}^{-1}$ is due to the carboxylic acid $\mathrm{O}-\mathrm{H}$ stretch vibration. These indicate that there are oxygencontaining functional groups on the surface of OMC [12]. In curve (b), L-proline is constituted of the peaks of $\mathrm{C}=\mathrm{O}$ stretching vibration at 1623 $\mathrm{cm}^{-1}$, and $\mathrm{C}-\mathrm{H}, \mathrm{N}-\mathrm{H}, \mathrm{O}-\mathrm{H}$ stretching vibration in the range of 2500 to $3500 \mathrm{~cm}^{-1}$. While in the copolymer of PPOMC film (c), the peaks at $3447 \mathrm{~cm}^{-1}(\mathrm{C}-\mathrm{H}, \mathrm{N}-\mathrm{H}, \mathrm{O}-\mathrm{H}$ stretching vibration) obviously broaden due to poly-reaction of L-proline and the peaks of $\mathrm{C}=\mathrm{O}$ stretching vibration shifts to $1639 \mathrm{~cm}^{-1}$ [18]. It is obvious that the transmittance of OMC monomer is quite weak, and the fine structures of curve (b) disappeared in curve (c), which can be account for the polymerization of L-proline and the deposition of OMC.

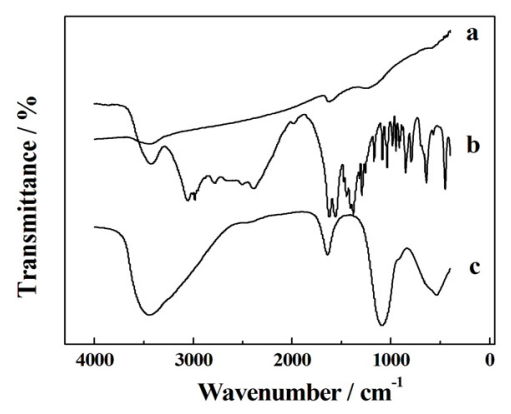

Fig. 3. FTIR spectra of OMC (a), L-proline (b) and PPOMC (c).

\section{EIS studies}

EIS is a simple and powerful tool for characterizing the interface properties of the electrode surfaces with different modifications. The Nyquist diagrams of bare GCE(a), PP/GCE (b), OMC/GCE(c), and PPOMC/GCE(d) in $\left[\mathrm{Fe}(\mathrm{CN})_{6}\right]^{3-/ 4-}$ solution were illustrated in Fig. 4 and the equivalent circuit (inset of Fig. 4 ) was chosen to fit the obtained impedance data. This equivalent circuit consists of the electrolyte solution resistance $\left(R_{s}\right)$, the double layer capacitance $\left(\mathrm{C}_{\mathrm{dl}}\right)$, electron-transfer resistance $\left(R_{c t}\right)$ and the Warburg impedance $\left(Z_{w}\right)$. After fitting the data, the $R_{c t}$ values obtained were $3.25 \mathrm{k} \Omega$ for the bare GCE (a), $6.88 \mathrm{k} \Omega$ for PP/GCE (b), $1.22 \mathrm{k} \Omega$ for OMC/GCE (c) and $2.15 \mathrm{k} \Omega$ for PPOMC/GCE (d). These indicate $\mathrm{PP}$ has block effect on $\left[\mathrm{Fe}(\mathrm{CN})_{6}\right]^{3-/ 4-}$ redox reaction, while OMC can form good electron pathway between the electrode and electrolyte. 
However, these split the difference effect at the PPOMC modified layer. It is probably attributed to counteracts the functions of mixed modified layer to the redox of $\left[\mathrm{Fe}(\mathrm{CN})_{6}\right]^{3-/ 4-}[19]$.

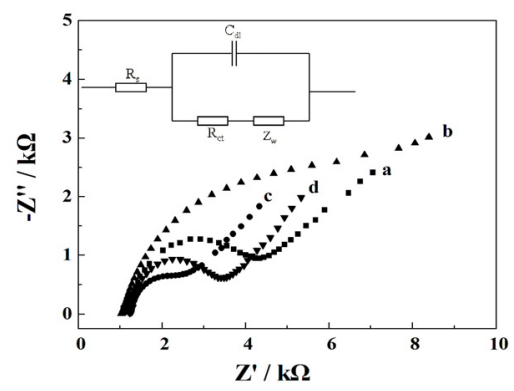

Fig. 4. EIS of bare GCE (a), PP/GCE (b), OMC/GCE (c), and PPOMC/GCE in $5 \mathrm{mmol} / \mathrm{L}$ $\mathrm{K}_{3}\left[\mathrm{Fe}_{3}(\mathrm{CN})_{6}\right]+0.1 \mathrm{~mol} / \mathrm{L} \mathrm{KCl}$. Insert is equivalent circuit for the modified electrode.

\section{Electrochemical behaviors of estrogens}

Fig. 5 described the electrochemical behaviors of natural estrogens (including estradiol, estrone and estriol) at different electrodes after $5 \mathrm{~min}$ open-circuit accumulation. As shown in Fig. 5A, CV of $2 \times 10^{-6} \mathrm{~mol} \mathrm{~L}^{-1}$ estradiol(E2) in $0.1 \mathrm{~mol} \mathrm{~L}^{-1}$ PBS $(\mathrm{pH} 7.4)$ at the PPOMC/GCE(d) was presented in comparison with that at the correspondingly prepared OMC/GCE(c), PP/GCE(b) and bare GCE(a). At bare GCE(a), estradiol generated a very small oxidation peak, while at PP/GCE(b) and OMC/GCE(c), estradiol presented much larger oxidation currents. However, a better formed anodic peak of estradiol appeared at PPOMC/GCE(d), whose oxidation peak current was about 20 times of that at bare $\operatorname{GCE}(\mathrm{a})$. This demonstrates a composite electrocatalytic activity of PP and OMC towards the oxidation of estradiol. Since only one peak occurred, it is an irreversible electrode process for estradiol oxidation. Estrone(E1) and estriol(E3) displayed similar electrochemical behaviors on the different electrodes because of the similarity of their molecular structures (Fig. 5B and Fig. 5C).
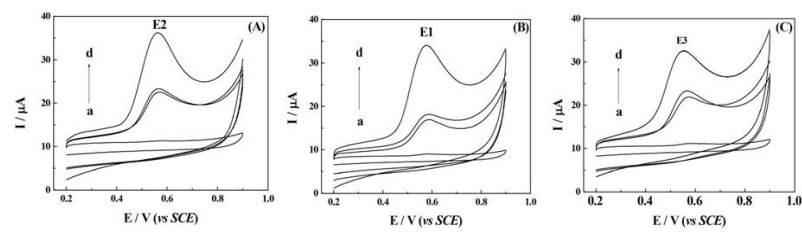

Fig. 5. $C V s$ in $0.1 \mathrm{~mol} \mathrm{~L}^{-1} \mathrm{PBS}$ (7.4) containing 2 $\mu \mathrm{mol} L^{-1}$ estradiol E2 (A), $10 \mu \mathrm{mol} L^{-1}$ estrone E1(B) and $10 \mu \mathrm{mol} L^{-1}$ estriol E3 at bare GCE(a); PP/GCE(b); OMC/GCE(c); PPOMC/GCE $(d)$. The accumulation time is $5 \mathrm{~min}$ at open-circuit. Scan rate is $0.1 \mathrm{Vs}^{-1}$.

\section{Linearity, detection limit and interferences}

Under the optimized conditions, the SWV after 5-min accumulation time were recorded in Fig. 6 and the inset of Fig. 6 was the calibration curve for the determination of estradiol. The oxidation peak current of estradiol was proportional to its concentration over the range from $1.0 \times 10^{-8}$ to $2.0 \times 10^{-6} \mathrm{~mol} \mathrm{~L}^{-1}$. Calibration equation can be described as follows: $I_{p}(\mu A)=1.025+16.23 C$ $\left(\mu \mathrm{mol} \mathrm{L}{ }^{-1}\right)$, with a correlation coefficient of 0.999 . And the limit of detection was evaluated to be $5.0 \times 10^{-9} \mathrm{~mol} \mathrm{~L}^{-1}$ based on a signal-to-noise ratio of $3(\mathrm{~S} / \mathrm{N}=3)$. Table 1 displayed the comparison of PPOMC/GCE with other modified electrodes for detecting estradiol previously reported [1-4, 6-7].

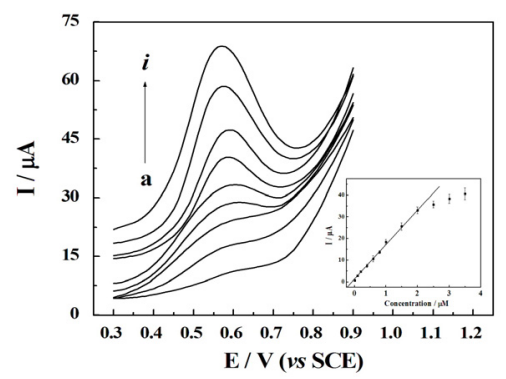

Fig. 6. SWVs of the PPOMC/GCE in $0.1 \mathrm{~mol} \mathrm{~L}^{-1}$ PBS (pH 7.4) solutions containing different concentrations of estradiol $\left(a \rightarrow i: 1.0 \times 10^{-8} \rightarrow 2.0 \times 10^{-6}\right.$ $\mathrm{mol} \mathrm{L}^{-1}$ ) after accumulation $5 \mathrm{~min}$; inset is the calibration curve for the determination of estradiol.

Tab1 Comparison of the proposed method with others

\begin{tabular}{|c|c|c|c|}
\hline Methods & $\begin{array}{l}\text { Linear range } \\
\qquad(\mu \mathrm{M})\end{array}$ & $\begin{array}{l}\text { LOD } \\
(\mu \mathrm{M})\end{array}$ & Ref. \\
\hline bare GCE & 40-1000 & 10 & [1] \\
\hline $\begin{array}{c}\text { CNT- } \\
\mathrm{Ni}(\text { Cyclam }) / \mathrm{GCE}\end{array}$ & $0.5-40$ & 0.06 & [2] \\
\hline $\begin{array}{c}\text { Nano Pt- } \\
\text { MWNT/GCE }\end{array}$ & $0.5-15$ & 0.18 & [3] \\
\hline Nano $\mathrm{Al}_{2} \mathrm{O}_{3} / \mathrm{GCE}$ & $0.4-40$ & 0.08 & [4] \\
\hline $\begin{array}{c}\text { MWNT- } \\
\text { Nafion/GCE }\end{array}$ & $0.25-10$ & 0.01 & [6] \\
\hline $\begin{array}{l}\text { Poly-serine/ } \\
\text { GCE }\end{array}$ & $0.1-30$ & 0.02 & [7] \\
\hline PPOMC/GCE & $0.01-2.0$ & 0.005 & $\begin{array}{l}\text { This } \\
\text { work }\end{array}$ \\
\hline
\end{tabular}

The influences of other foreign species on the peak current of estradiol were investigated and the results were as the following. For $1 \mu \mathrm{mol} \mathrm{L}{ }^{-1}$ estradiol, 500-fold of $\mathrm{Na}^{+}, \mathrm{K}^{+}, \mathrm{Mg}^{2+}, \mathrm{Ca}^{2+}, \mathrm{Cl}^{-}$, $\mathrm{SO}_{4}{ }^{2-}, \mathrm{Ac}^{-}$, glucose and sucrose, 100-fold of dopamine, uric acid, ascorbic acid, epinephrine, leucine, alanine, phenylalanine, cysteine and phenol derivatives almost do not interfere with the determination of estradiol. However, 
because of the overlapping peak potential, the influences of tyrosine and tryptophan are

\section{Acknowledgements}

This work was supported by the National Natural Science Foundation of China (No. 10804067, 20975066, 41140031, 61171033), Leading Academic Discipline Project of Shanghai Municipal Education Commission (J50102).

\section{References}

[1] B. Salcı, I. Biryol, Voltammetric Investigation of $\beta$ estradiol, Journal of Pharmaceutical and Biomedical Analysis 28, 753-759 (2002); doi: 10.1016/s0731-7085(01)00676-8

[2] X. Liu, D.K.Y. Wong, Electrocatalytic Detection of Estradiol at a Carbon Nanotube|Ni(Cyclam) Composite Electrode Fabricated Based on A Two-factorial Design, Analytica Chimica Acta 594, 184-191 (2007); doi: 10.1016/j.aca.2007.05.043

[3] X. Lin, Y. Li, A Sensitive Determination of Estrogens with a Pt Nano-Clusters/Multi-Walled Carbon Nanotubes Modified Glassy Carbon Electrode, Biosensors and Bioelectronics 22, 253-259 (2006); doi: 10.1016/j.bios.2006.01.005

[4] Q. He, S. Yuan, C. Chen, S. Hu, Electrochemical Properties of Estradiol at Glassy Carbon

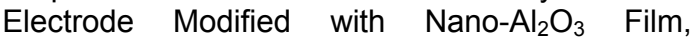
Materials Science and Engineering: $C$ 23, 621625 (2003); doi: 10.1016/s0928-4931(03)00053-5

[5] C. Hu, C. Yang, S. Hu, Hydrophobic Adsorption of Surfactants on Water-soluble Carbon Nanotubes: A Simple Approach to Improve Sensitivity and Antifouling Capacity of Carbon Nanotubes-based Electrochemical Sensors, Electrochemistry Communications 9, 128-134 (2007); doi: 10.1016/j.elecom.2006.08.055

[6] N. Terui, B. Fugetsu, S. Tanaka, Voltammetric Behavior and Determination of $17 \beta$-Estradiol at Multi-Wall Carbon Nanotube-Nafion Modified Glassy Carbon Electrode, Analytical Sciences 22, 895-898 (2006); doi:10.2116/analsci.22.895

[7] J.C. Song, J. Yang, X.M. Hu, Electrochemical Determination of Estradiol Using a Poly(L-serine) Film-modified Eelectrode, Journal of Applied Electrochemistry 38, 833-836 (2008); doi: $10.1007 / \mathrm{s} 10800-008-9520-8$

[8] Y.S. Kim, H.S. Jung, T. Matsuura, H.Y. Lee, T. Kawai, M.B. Gu, Electrochemical Detection of $17 \beta$-estradiol Using DNA Aptamer Immobilized Gold Electrode Chip, Biosensors and Bioelectronics 22, 2525-2531 (2007); doi: 10.1016/j.bios.2006.10.004

[9] M. Murugananthan, S. Yoshihara, T. Rakuma, N. Uehara, T. Shirakashi, Electrochemical Degradation of $17 \beta$-estradiol (E2) at BoronDoped Diamond (Si/BDD) Thin Film Electrode, Electrochimica Acta 52, 3242-3249 (2007); doi: 10.1016/j.electacta.2006.09.073 serious.

[10] Z. Zhu, X. Li, Y. Zeng, W. Sun, Ordered Mesoporous Carbon Modified Carbon Ionic Liquid Electrode for the Electrochemical Detection of Double-Stranded DNA, Biosensors and Bioelectronics 25, 2313-2317 (2010); doi: 10.1016/j.bios.2010.03.019

[11] D. Yang, L. Zhu, X. Jiang, L. Guo, Sensitive Determination of Sudan $\mathrm{I}$ at an Ordered Mesoporous Carbon Modified Glassy Carbon Electrode, Sensors and Actuators B: Chemical 141, 124-129 (2009); doi: 10.1016/j.snb.2009.05.030

[12] M. Zhou, J. Ding, L.P. Guo, Q.K. Shang, Electrochemical Behavior of L-Cysteine and Its Detection at Ordered Mesoporous CarbonModified Glassy Carbon Electrode, Analytical Chemistry 79, 5328-5335 (2007); doi: 10.1021/ac0703707

[13] J.J. Feng, J.J. Xu, H.Y. Chen, Direct Electron Transfer and Electrocatalysis of Hemoglobin Adsorbed on Mesoporous Carbon through Layerby-layer Assembly, Biosensors and Bioelectronics 22, 1618-1624 (2007); doi: 10.1016/j.bios.2006.07.022

[14] D. Zheng, J. Ye, L. Zhou, Y. Zhang, C. Yu, Electrochemical Properties of Ordered Mesoporous Carbon Film Adsorbed onto a SelfAssembled Alkanethiol Monolayer on Gold Electrode, Electroanalysis 21, 184-189 (2009); doi: 10.1002/elan.200804445

[15] X.L. Luo, J.J. Xu, J.L.Wang, H.Y. Chen, Electrochemically Deposited Nanocomposite of Chitosan and Carbon Nanotubes for Biosensor Application, Chemical Communications, 16, 2169-2171 (2005); doi: 10.1039/B419197H

[16] S. Jun, S.H. Joo, M. Kruk, M. Jaroniec, Z. Liu, T. Ohsuna, Synthesis of New, Nanoporous Carbon with Hexagonally Ordered Mesostructure, Journal of American Chemical Society, 122, 10712-10713 (2000); doi: 10.1021/ja002261e

[17] D. Zhao, J. Feng, Q. Huo, N. Melosh, G.H. Fredrickson, B.F. Chmelka, G.D. Stucky, Triblock Copolymer Syntheses of Mesoporous Silica with Periodic 50 to 300 Angstrom Pores, Science 279, 548-552 (1998); doi: 10.1126/science. 279.5350 .548

[18] X. Liu, L. Luo, Y. Ding, D. Ye, Poly-glutamic Acid Modified Carbon Nanotube-doped Carbon Paste Electrode for Sensitive Detection of L-tryptophan. Bioelectrochemistry 82, 38-45 (2011); doi: 10.1016/j.bioelechem.2011.05.001

[19] G.P. Jin, X.Q. Lin, Y.F. Ding, Glassy Carbon Electrodes Modified with Mixed Covalent Monolayers of Choline, Glycine, and Glutamic Acid for the Determination of Phenolic Compounds, Journal of Solid State Electrochemistry 10, 987-994 (2006); doi: 10.1007/s10008-005-0068-9 